\title{
Algumas Notas sobre a Incorporação e a Hierarquia dos Tratados em Matéria de Direitos Humanos na Ordem Jurídica Brasileira, Especialmente em Face do Novo $\S 3^{\circ}$ do Art. $5^{\circ}$ da Constituição de 1988
}

Ingo Wolfgang Sarlet'

\section{Notas introdutórias}

A Emenda Constitucional no 45, de 8 de dezembro de 2004 (doravante denominada EC 45), que implementou, após longa e tormentosa tramitação no Congresso Nacional, a assim chamada Reforma do Poder Judiciário, introduziu várias disposiçōes expressamente relativas aos direitos humanos e fundamentais e outras - embora versando sobre diversos aspectos - com maior ou menor impacto sobre o sistema de direitos fundamentais da nossa Constituição.

O quanto cada uma das alteraçōes e inserçōes efetivadas virá a atuar positiva ou negativamente em matéria de direitos fundamentais ainda está longe de poder ser avaliado com alguma segurança, considerando a necessidade de amadurecimento da discussão em nível doutrinário e jurisprudencial, visto que, a despeito do debate já iniciado antes mesmo da promulgação da reforma, somente com a sua entrada em vigor é que se está a refletir com base em texto efetivamente incorporado à Constituição, somente modificável por outra reforma ou pela interpretação jurisdicional, que, de resto, poderá até mesmo levar à declaração de inconstitucionalidade de alguns pontos da EC 45.

Aliás, não são poucas as manifestações sustentando a violação de cláusulas pétreas da Constituição, inclusive acompanhadas de ações diretas de inconstitu-

1 Pós-Doutorado em Direito (Universidade de Munique e Instituto Max-Planck de Direito Social Estrangeiro e Internacional). Professor Titular da Faculdade de Direito e dos Cursos de Mestrado e Doutorado do Programa de Pós-Graduaçāo em Direito da PUC/RS. Professor da Escola Superior da Magistratura (AJURIS). Juiz de Direito (RS). 
cionalidade, como foi o caso, por exemplo, da controvérsia em torno do controle externo da Magistratura e do Ministério Público (com decisão do Supremo Tribunal Federal em prol de sua constitucionalidade, no que diz com a forma e estrutura dos respectivos Conselhos Superiores) e da federalização da competência para o julgamento dos casos de grave violação dos direitos humanos, esta última ainda pendente de decisão por parte do Supremo Tribunal Federal.

Nesta perspectiva, objetivando acima de tudo integrar o processo de discussão e contribuir para a reflexão sobre as alternativas hermenêuticas mais afinadas com o mandamento da maximização da eficácia e efetividade dos direitos fundamentais, tal qual consagrado pelo art. $5^{\circ}, \mathbb{S} 1^{\circ}$, da Constituição Federal (na seqüência $\mathrm{CF}$ ), o nosso propósito é o de analisar as possíveis conseqüências da inserção de um terceiro parágrafo no art. $5^{\circ} \mathrm{da} \mathrm{CF}$, versando sobre a incorporação de tratados internacionais em matéria de direitos humanos ao sistema constitucional, dispondo que "os tratados e convençōes internacionais sobre direitos humanos que forem aprovados, em cada Casa do Congresso Nacional, em dois turnos, por três quintos dos votos dos respectivos membros, serão equivalentes às emendas constitucionais". O novo dispositivo, em princípio, veio para complementar o $\$ 2^{\circ}$ do mesmo artigo, que consagrou expressamente a abertura material dos direitos fundamentais no sistema constitucional nacional, ${ }^{2}$ agasalhando norma geral inclusiva, ${ }^{3}$ que - notadamente no que concerne aos tratados de direitos humanos e seu regime jurídico interno - tem sido objeto de farta produção doutrinária e acirrado debate, o qual, todavia, dadas as limitações do presente ensaio, aqui não será retomado em toda a sua amplitude.

Considerando, portanto, o teor do novo dispositivo (no caso, o $\$ 3^{\circ}$ do art. $\left.5^{\circ}\right)$, não é de se estranhar que no âmbito da doutrina especializada a discussão tenha assumido novos contornos, acompanhada de grande variedade de posicionamentos, que alcançam desde a discussão em torno do regime jurídico dos tratados anteriores, até problemas vinculados ao novo processo de incorporação (por exemplo, o seu caráter facultativo ou cogente) e aspectos atinentes à hierarquia dos tratados incorporados pelo rito das emendas constitucionais, havendo até mesmo quem esteja a questionar a legitimidade constitucional da inovação trazida pela EC 45 neste particular. Diante deste quadro, é nosso propósito - ao revisitar o tema - retomar, aperfeiçoar e complementar uma série de considerações sobre pelo menos parte das questōes ventiladas no âmbito da controvérsia doutrinária, com o intuito de contribuir de algum modo para, se não um certo avanço nesta seara, pelo menos para alguma sistematização e sedimentação do debate, que, como já frisado, apenas iniciou, de vez que não houve, ainda, aprovação de emen-

\footnotetext{
2 Sobre o tema, ver, dentre outros, o nosso A eficácia dos direitos fundamentais, 6. ed., Porto Alegre: Livraria do Advogado, 2006, p. 92 ss.

3 Cf., na esteira de farta e tradicional doutrina, que de há muito rechaça a fórmula do inclusio unius alterius est exclusius, a formulaçāo de Juarez Freitas, $A$ interpretação sistemática do direito, 4. ed., São Paulo: Malheiros, 2004, p. 211-212, com destaque para a funçāo atribuída à Declaraçāo Universal da ONU, de 1948.
} 
da constitucional incorporando tratado internacional em matéria de direitos humanos, assim como ainda não houve pronunciamento dos Tribunais Superiores, notadamente do Supremo Tribunal Federal, sobre a matéria. Por fim, adverte-se o leitor de que se em boa parte se está a reproduzir textos anteriores, houve aqui uma ampliação e atualização importante do debate, seja mediante a reavaliação e pelo reforço de alguns argumentos, seja pela inserção de novas questōes e de literatura não considerada nas duas versões anteriores, ${ }^{4}$ pelo que consideramos justificada a publicação desta nova versāo como um artigo autônomo.

\section{O § 3 do art. 5 da Constituição e seus possíveis reflexos no que diz com a incorporação e hierarquia dos direitos humanos e fundamentais com sede em tratados internacionais}

A EC 45, que cuidou da reforma do Poder Judiciário, acrescentou - como já frisado - um $\$ 3^{\circ}$ ao art. $5^{\circ}$ da nossa Constituição. Segundo este dispositivo, "Os tratados e convençōes internacionais sobre direitos humanos que forem aprovados, em cada Casa do Congresso Nacional, em dois turnos, por três quintos dos votos dos respectivos membros, serão equivalentes às emendas constitucionais." Tal preceito - para além de reforçar (pelo menos no que diz com o direito constitucional positivo) a corrente distinção entre direitos humanos e direitos fundamentais a partir do seu respectivo plano de reconhecimento e proteção jurídico-positivo ${ }^{5}$ - acabou por inserir no texto constitucional uma norma (no caso, uma regra do tipo procedimental, em primeira linha) dispondo sobre a forma de incorporação ao direito interno dos tratados em matéria de direitos humanos, que, interpretada em sintonia com o art. $5^{\circ}, \mathbb{} \leqslant 2^{\circ}$, pode ser compreendida como assegurando - em princípio e em sendo adotado tal procedimento - a condição de direitos formal e materialmente fundamentais aos direitos consagrados no plano das convençōes internacionais. Que tal exegese não é a única possível, e que, a teor do já anunciado na introdução, uma série de pontos controversos em torno do novo dispositivo constitucional e da sua melhor interpretação tem sido levantados, constitui justamente o desafio que nos propomos a enfrentar com particular

\footnotetext{
4 Foram publicados dois artigos de nossa autoria versando sobre a temática, um mais extenso, incluindo uma digressão sobre a distinçāo entre direitos humanos e direitos fundamentais e sobre a abertura material do catálogo constitucional (Os direitos fundamentais, a reforma do Judiciário e os tratados internacionais de direitos humanos: notas em torno dos $\$ \$ 2^{\circ}$ e $3^{\circ}$ do art. $5^{\circ}$ da Constituição de 1988, Revista de Direito do Estado, $\mathrm{n}^{\mathrm{o}}$ 1, jan./mar. 2006, Rio de Janeiro: Renovar, p. 59-99) e outro mais reduzido, priorizando a discussão em torno do novo $\$ 3^{\circ}$ do art. $5^{\circ}$ da Constituição (A reforma do Judiciário e os tratados de direitos humanos: algumas notas sobre o novo $\$ 3^{\circ}$ do art. $5^{\circ}$ da Constituição, Interesse Público no 37, maio/jun. 2006, p. 49-64, também publicado na Revista do Instituto de Hermenêutica Jurídica no 4, Porto Alegre, 2006, p. 183-200).

5 Sobre esta distinção, adotada com base nas diferenças entre o plano internacional de positivaçāo (direitos humanos) e o plano constitucional (direitos fundamentais) ver o nosso $A$ eficácia dos direitos fundamentais..., p. 33-42.
} 
atenção neste segmento, ainda que sem a pretensão de esgotar as diversas alternativas hermenêuticas disponíveis.

Em primeiro lugar, convém destacar que é pelo menos questionável o entendimento - por mais sedutor que seja - de que por força da EC 45 todos os tratados em matéria de direitos humanos já incorporados ao sistema jurídico brasileiro possam ser considerados como equivalentes às emendas constitucionais, já que não há como aplicar neste caso o argumento da recepção quando se trata de procedimentos legislativos distintos, ainda que haja compatibilidade material, como se fosse possível transmutar um decreto legislativo aprovado pela maioria simples do Congresso Nacional em emenda constitucional que exige uma maioria reforçada de três quintos dos votos, sem considerar os demais limites formais das emendas à Constituição. ${ }^{6}$ Em sentido diverso, contudo, há quem defenda, fundado em respeitável doutrina, a recepção dos tratados anteriores - naquilo que efetivamente versam sobre direitos humanos (no sentido de bens jurídicos indispensáveis à natureza humana ou à convivência social) - como se tivessem sido incorporados pelo rito mais rigoroso das emendas constitucionais, assegurandolhes a respectiva supremacia normativa, no âmbito do que se costuma designar de recepçāo material. ${ }^{7}$

Tal entendimento, como ainda teremos oportunidade de ver ao longo da exposição subseqüiente, dificilmente se revela como sustentável, ${ }^{8}$ considerando a incompatibilidade total de rito (e natureza) dos decretos legislativos e das emendas constitucionais. A comparação entre lei ordinária e lei complementar - ainda que pressuponha diferença de rito e quorum de aprovação distinto - não pode ser, salvo melhor juízo, transposta automaticamente para os decretos legislativos e emendas constitucionais, já que tanto os decretos quanto as emendas não cumprem a mesma função das leis (ordinárias e complementares), isto sem falar na hierarquia constitucional das emendas, que passam a integrar a Constituição, o que não ocorre com as leis. Em caráter alternativo - mas substancialmente diverso da tese da recepçāo -, há quem defenda que os tratados internacionais (que já são materialmente constitucionais e portanto já possuem hierarquia constitucional por força do próprio art. $5^{\circ}, \mathbb{S} 2^{\circ}$, da CF!) também poderāo ser formalmente constitucionais, caso forem aprovados, a qualquer momento, pelo procedimento reforçado instituído pelo art. $5^{\circ}, \S 3^{\circ} .^{9}$

\footnotetext{
- Neste sentido, registra-se a posição de PIOVESAN, Flávia. Reforma do judiciário e direitos humanos. In: TAVARES, André Ramos; LENZA, Pedro; ALARCON, Pietro de Jesus Lora (Org.). Reforma do judiciário analisada e comentada. São Paulo: Método, 2005, p. 72.

Cf. TAVARES, André Ramos. Reforma do judiciário no Brasil pós-88: (des)estruturando a justiça. Comentários completos à emenda constitucional n² 45/04. São Paulo: Saraiva, 2005, p. 47-48; e, também, FRANCISCO, José Carlos. Bloco de constitucionalidade e recepção dos tratados internacionais. In: TAVARES, André Ramos; LENZA, Pedro; ALARCON, Pietro de Jesus Lora (Org.). Reforma do judiciário analisada e comentada. São Paulo: Método, 2005, p. 103-105.

8 Ver, justamente neste sentido, o recente e enfático pronunciamento de PIOVESAN, op. cit., p. 72.

9 Neste sentido, precisamente a conclusão de MAZZUOLI, Valério de Oliveira. O novo $₫ 3^{\circ}$ do art. $5^{\circ}$ da Constituição e sua eficácia. Revista da Ajuris, v. 32, nº 98, Porto Alegre, jun. 2005, p. 321.
} 
Há que observar, neste contexto, que a recepção - com qualidade de emenda constitucional - dos tratados anteriores acabaria sendo, em determinadas circunstâncias, até menos vantajosa do que a chancela de sua constitucionalidade e fundamentalidade em sentido apenas material, já que, como voltaremos a discutir mais adiante, poderiam ser objeto de declaração de inconstitucionalidade pelo Poder Judiciário, se este vislumbrasse uma ofensa aos limites materiais à reforma constitucional. Assim, como afirma Flávia Piovesan, quanto aos tratados incorporados pelo rito mais rigoroso das emendas, em relação a estes se estaria apenas (?) a reforçar - no plano formal - a sua hierarquia constitucional material desde logo assegurada por força do art. $5^{\circ}, \mathbb{} 2^{\circ}$, da $C F{ }^{10}$ Que, de fato, tal interpretação talvez não represente, ainda mais se compreendida isoladamente, um avanço significativo, bem como - tal qual oportunamente adverte André Ramos Tavares - se revela problemática, se com isso se estiver pretendendo fundamentar a constitucionalidade dos tratados apenas no novo $\$ 3^{\circ}$ do art. $5^{\circ}$ da CF e não - como deveria ser - já com base no $\$ 2^{\circ}$ do mesmo dispositivo, introduzido pelo Constituinte de $1988,{ }^{11}$ deve evidentemente ser levado em conta.

$O$ fato é que independentemente do problema da hierarquia dos tratados incorporados pelo sistema praticado até a EC 45 - do qual voltaremos a nos ocupar mais adiante - resta, notadamente em função da redação do novo $\$ 3^{\circ}$ do art. $5^{\circ}$, uma série de questões a serem solvidas e que aqui serão apenas anunciadas e analisadas em caráter ilustrativo e essencialmente especulativo, visto que a doutrina e a jurisprudência apenas estão iniciando a discussão da temática. Acima de tudo, nos parece relevante registrar, desde logo, que é possível - a despeito de todas as dificuldades - outorgar ao novo instituto uma exegese que, no seu conjunto, não represente - embora plenamente justificadas as preocupaçōes reveladas no âmbito da doutrina $a^{12}$ - necessariamente um retrocesso em relação ao entendimento hoje já majoritário no seio da doutrina, ao reconhecer a condição de direitos fundamentais em sentido material aos direitos humanos constitucionalizados.

Assim, apontando já um aspecto positivo, afirma-se que com a adoção do procedimento previsto no art. $5^{\circ}, \mathbb{3} 3^{\circ}$, da $C F$, os tratados em matéria de direitos humanos passariam a integrar o bloco de constitucionalidade, que representa a reunião de diferentes diplomas normativos de cunho constitucional, que atuam, em seu conjunto, como parâmetro do controle de constitucionalidade, o que configura um avanço em relação à posição mais restritiva do nosso Supremo Tribunal Federal na matéria, que, por exemplo, não outorga força normativa superior ao Preâmbulo da Constituição. ${ }^{13}$ A despeito da correção do argumento, não se deve, contudo, perder de vista que independentemente de sua incorporação à Consti-

10 Cf. PIOVESAN, op. cit., p. 72.

11 Cf. TAVARES, op. cit., p. 42.

12 Cf., por todos, GALINDO, George Rodrigo Bandeira. A reforma do Judiciário como retrocesso para a proteção internacional dos direitos humanos: um estudo sobre o novo $\$ 3^{\circ}$ do artigo $5^{\circ}$ da Constituição Federal, Cena Internacional, ano 7, $\mathrm{n}^{\circ}$ 1, 2005, p. 1-22.

13 Neste sentido, novamente, FRANCISCO, op. cit., p. 99-101. 
tuição formal, os direitos originários dos tratados internacionais, pelo menos para quem já vinha sustentando a sua condição de materialmente fundamentais (à luz do já analisado art. $5^{\circ}, \$ 2^{\circ}$ ) já seriam parte integrante do nosso bloco de constitucionalidade, que não abrange necessariamente apenas normas constitucionais embasadas em disposições expressas de textos com hierarquia constitucional. Além disso, há quem questione seriamente até mesmo a constitucionalidade do próprio $\$ 3^{\circ}$ do art. $5^{\circ}$, de modo que, a prevalecer este entendimento e a posição ainda adotada pelo Supremo Tribunal Federal - ao reconhecer a hierarquia apenas legal dos tratados - estes não integrariam o bloco de constitucionalidade. Da mesma forma, argumenta-se que a inovação trazida pela EC 45 é inconstitucional por violar os limites materiais à reforma constitucional, no sentido de que se acabou dificultando o processo de incorporação dos tratados internacionais sobre direitos humanos e chancelando o entendimento de que os tratados não incorporados pelo rito das emendas constitucionais teriam hierarquia meramente legal, de tal sorte que restou restringido, desta forma, o próprio regime jurídico-constitucional dos direitos fundamentais oriundos dos tratados. ${ }^{14}$

Outro aspecto digno de nota - e vinculado ao problema da alegada inconstitucionalidade da inovação - diz respeito ao caráter compulsório ou facultativo da adoção do procedimento mais rigoroso das emendas constitucionais, especialmente em face da redação do dispositivo ("os tratados que forem incorporados..."), que, no mínimo, dá ensejo a tal dúvida e sustenta a adoção do entendimento que a incorporação mediante o procedimento das emendas poderia ser opcional. Tal argumento assume ainda maior relevo em se considerando que - sob o ponto de vista da forma - a incorporação dos tratados em matéria de direitos humanos - consoante já apontado - se tornou mais dificultada, o que, em princípio, poderia ser considerado como contraditório, considerando a abertura material consagrada no art. $5^{\circ}, \$ 2^{\circ}$, e o princípio (fundamental) da prevalência dos direitos humanos no plano das relações internacionais do Brasil estabelecido no art. $4^{\circ}$ da nossa Lei Fundamental.

Com relação a este aspecto, parece-nos que há sim pelo menos espaço para uma interpretação teleológica e sistemática em prol da compulsoriedade do procedimento reforçado das emendas constitucionais. Com efeito, tendo em mente que a introdução do novo $\mathbb{3} 3^{\circ}$ teve por objetivo (ao menos, cuida-se da interpre-

\footnotetext{
I4 Neste sentido, mencionando a existência de um anacronismo e apontando para a "duvidosa constitucionalidade" da alteração efetuada pela $E C n^{2} 45 / 04$, ver a opinião do advogado criminalista e professor da Universidade de Brasília, COSTA, Aldo de Campos. Direitos humanos. Disponível em: <http:// www.unb.br/fd/colunas_Prof/aldo_campos/aldo_01.htm>. Acesso em: 12 fev. 2006. De forma mais enfática, ver LOPES, Anselmo Henrique Cordeiro. A força normativa dos tratados internacionais de direitos humanos e a Emenda Constitucional $n^{\circ}$ 45/2004. Disponível em: <http://wwwl.jus.com.br/doutrina/texto. asp? id =6157>. Acesso em: 12 fev. 2006. Na mesma linha, SGARBOSSA, Luís Fernando. A emenda constitucional $n^{\circ} 45 / 04$ e o novo regime jurídico dos tratados internacionais em matéria de direitos humanos. Disponivel em: <http://wwwl.jus.com.br/doutrina/texto.asp?id=6272>. Acesso em: 11 fev. 2006 , condena o fato de ter havido frustraçāo da intenção do Constituinte no sentido de assegurar a inclusāo automática dos direitos humanos no catálogo constitucional.
} 
tação mais afinada com a ratio e o telos do $\$ 2^{\circ}$ ) resolver - ainda que remanescentes alguns problemas - de modo substancial o problema da controvérsia sobre a hierarquia dos tratados em matéria de direitos humanos, antes incorporados por Decreto Legislativo e assegurar aos direitos neles consagrados um status jurídico diferenciado, compatível com sua fundamentalidade, poder-se-á sustentar que, a partir da promulgação da EC 45, a incorporação destes tratados deverá ocorrer pelo processo mais rigoroso das reformas constitucionais. Quanto à objeção de que com isso se estaria a dificultar a incorporação dos tratados e convenções em matéria de direitos humanos (lembre-se que há os que sustentam até mesmo a dispensa de qualquer ato formal de incorporação para além da ratificação) há como revidar com o argumento de que, além de assegurar aos direitos dos tratados pelo menos uma hierarquia constitucional equivalente às normas constitucionais do tipo derivado (para usar a terminologia mais habitual) resta enrobustecida a legitimação democrática desses direitos, o que, por sua vez, concorre para a sua maior força normativa - em suma, para uma pretensāo de eficácia e efetividade reforçadas - indispensável também para reforçar a posição do nosso país em face da comunidade internacional.

A importância de uma reforçada legitimidade democrática assume ainda maior relevo em se considerando que, uma vez incorporados por via de emenda constitucional, os direitos (agora também formalmente) agregados ao catálogo constitucional não apenas reformam a própria Constituição, mas também assumem a condição - pelo menos é isso que se advoga - de limites materiais à própria reforma, sendo, após, insuscetíveis de supressão e esvaziamento, ainda que por nova emenda constitucional. Com isso - é bom que se frise -, não se está evidentemente a dizer que os direitos previstos nos tratados já incorporados antes da EC 45 não estejam jusfundamentalmente protegidos, visto que, embora não possam ser objeto de abolição direta por uma emenda (de vez que materialmente constitucionais e pelo fato de as emendas serem instrumentos de mudança formal da Constituição, exigindo, portanto, sempre alguma alteração no plano textual), reclamam proteção contra limitações e retrocessos de toda ordem, por conta de seu núcleo essencial e da incidência dos demais limites às limitações de direitos fundamentais, ${ }^{15}$ no que couber, temática que aqui, todavia, não poderá ser mais desenvolvida.

Também analisando a questão de modo crítico, Valério de Oliveira Mazzuoli observa, todavia, que por meio da incorporação por emenda constitucional, a reforma constitucional daí resultante poderia até mesmo piorar a proteção de direitos fundamentais, notadamente quando a nossa Constituição for mais benéfica, sendo preferível que se admitisse pura e simplesmente a condição de norma constitucional (sem previsão do rito) de modo a sufragar a posição de acordo com

\footnotetext{
15 Aqui estamos a nos referir aos assim designados limites dos limites (do alemão Schranken-Schranken) que compreendem as garantias constitucionais contra as restriçōes de direitos fundamentais, como é o caso da reserva de lei, do núcleo essencial e dos critérios da proporcionalidade.
} 
a qual deverá ser dada prevalência à norma mais favorável à pessoa humana. ${ }^{16} \mathrm{Tal}$ argumentação, conquanto bem articulada, há de ser tomada com certa reserva. Com efeito, se o tratado resultar necessariamente (portanto, nāo sendo viável uma interpretação conforme a Constituição) em uma situação pior para a pessoa humana do que a decorrente do nosso sistema constitucional positivo, não haverá de se incorporar o tratado neste particular, já que violador de "cláusula pétrea" de nossa Constituição, não sendo - no nosso sentir - juridicamente relevante o argumento de que tal análise demandaria demasiado trabalho (resultante de uma investigação de todos os projetos tramitando no Congresso), notadamente pelo fato de que o juízo definitivo de constitucionalidade (ou inconstitucionalidade) deverá ocorrer no âmbito do controle jurisdicional repressivo (ou, em caráter excepcional, preventivo), sempre à luz de um determinado instrumento legislativo e tendo por base a parametricidade da nossa Constituição. O que poderá - isto sim - resultar problemático é a hipótese em que a proteção internacional é mais favorável à pessoa, podendo, em tese, os órgãos jurisdicionais nacionais privilegiar o ordenamento constitucional, louvando-se no argumento das "cláusulas pétreas", situação que, embora deva ser rara (atualmente segue assumindo relevo apenas a questão da prisão civil do depositário infiel), não é de se excluir. Aqui o problema, novamente, conecta-se com uma adequada exegese do sentido e alcance da inovação - sem dúvida problemática, como se percebe - trazida pela EC 45. Como se cuida de tópico relativo à hierarquia dos tratados, voltaremos a nos manifestar a respeito.

Uma possivel vantagem da incorporação pelo rito das emendas constitucionais poderia residir no daí decorrente reforço do argumento - já corretamente sustentado com base no art. $5^{\circ}, \$ 2^{\circ}$, da CF - de que impossível (mesmo por emenda constitucional, como leciona Valério de Oliveira Mazzuoli) a denúncia do tratado por parte do Brasil, enrobustecendo não apenas a posição dos direitos humanos e agora também fundamentais no âmbito interno (desde que, é claro, se adote uma exegese que privilegie a força normativa desses direitos), mas também avança no concernente ao plano externo, das relações internacionais, enfatizando as vinculações assumidas pelo Brasil nesta seara ${ }^{17}$. Lembre-se, neste contexto, da pendência, no Supremo Tribunal Federal, de decisão sobre a necessidade de aprovação prévia do Congresso Nacional da denúncia do tratado pelo Presidente da República, ${ }^{18}$ o que se aplicaria - tal qual sustentado pelos autores da impug-

16 Cf. MAZZUOLI, op. cit., p. 323.

17 Ver, dentre outras, a argumentaçāo bem sustentada por MAZZUOLI, op. cit., p. 325 ss, destacando, com perspicácia, que, uma vez incorporada pelo rito introduzido pela EC 45 , a denúncia passaria a acarretar (ao contrário do que poderia ocorrer no sistema do art. $5^{\ddagger}, \$ 2^{\circ}$ ) a responsabilizaçāo do denunciante. No mesmo sentido, já discorrendo sobre a EC 45, consultar TAVARES, op. cit., p. 44, bem como as igualmente pertinentes ponderaçōes de GALINDO, op. cit., p. 15-16.

18 V. ADI 1625, relator Min. Maurício Corrêa (substituído pelo Ministro Eros Grau), onde se discute a inconstitucionalidade da denúncia unilateral da Convenção $\mathrm{n}^{2} 158$ da OIT. Registre-se que os Ministros Maurício Corrêa e Carlos Britto já votaram no sentido da procedência parcial da ação, sustentando a interpretação conforme a Constituição do Decreto Federal impugnado (DF $\mathrm{n}^{2} 2100$, de 20.12.1996) 
nação da denúncia presidencial no caso referido - inclusive a tratados incorporados antes da inserção do $\$ 3^{\circ}$ no art. $5^{\circ}$ da $C F$, já que não faz sentido que para a incorporação do tratado seja indispensável a aprovação pelo Congresso e para uma posterior denúncia se possa dispensar a intervenção do Legislativo. Note-se que além de o texto constitucional não conter nenhuma disposição que expressamente afaste esta interpretação, ela, pelo menos no concernente aos tratados de direitos humanos, resulta de uma interpretação sistemática a partir do art. $4^{\circ}$, II (prevalência dos direitos humanos nas relações internacionais) e do sentido do art. $5^{\circ}, \$ 2^{\circ}$, da $\mathrm{CF}$, além de amparada no princípio democrático e, a depender da hipótese, na proibição de retrocesso, incidente também no âmbito da proteção internacional dos direitos humanos. ${ }^{19}$

Outro problema - este mais de ordem técnico-legislativo - diz com a forma pelo qual o texto do tratado, uma vez incorporado pelo rito das emendas, passaria a ser inserido no texto constitucional. Com efeito, considerando que em regra os tratados são ratificados e incorporados na íntegra, resta saber se o texto aprovado seria inserido nos locais próprios da Constituição, se apenas os dispositivos que enunciam determinado direito seriam acrescidos ao catálogo constitucional (consoante a natureza do direito), se o texto do tratado seria simplesmente acrescido ao final da Constituição, ou mesmo se o texto incorporado pelo procedimento das emendas simplesmente representaria um texto constitucional em separado. A indagação, que já seria no mínimo procedente em termos de técnica legislativa, também o é pelo fato de que a distinção entre constituição formal e instrumental viabiliza a existência de mais de um texto (instrumento) com status de direito constitucional em sentido formal, como poderá ocorrer, a depender da técnica adotada, na hipótese de aplicação do novo regime de incorporação dos tratados.

Ainda no concernente ao procedimento, consoante percebido por Valério de Oliveira Mazzuoli, existe questão relativa ao momento da incorporação pelo rito da emenda constitucional (se vier a ser o caso), já que o novo $\$ 3^{\circ}$ do art. $5^{\circ}$ não suprimiu a fase prevista no art. 49 , inc. I, da CF, de tal sorte que a aprovação da emenda de incorporaçāo deverá sempre ser posterior à ratificação (portanto, pressuposta também a celebração pelo Presidente da República, a teor do art. 84, inc. VIII, da CF) do tratado regularmente vigente no âmbito internacional. ${ }^{20}$ Como igualmente bem aponta o referido autor, compromete a segurança jurídica (nacional e internacional) e os princípios que regem as relações internacionais deixar ao

para condicionar a denúncia ao referendo do Congresso Nacional. O Ministro Nelson Jobim, em contrapartida, pronunciou-se pela improcedência da ADI. Atualmente o processo encontra-se aguardando pronunciamento do Ministro Joaquim Barbosa (informaçāo de 9.9.2006).

19 Cf., entre nós e por todos, RAMOS, André de Carvalho, Teoria geral dos direitos humanos na ordem internacional, Rio de Janeiro: Renovar, 2005, p. 243. No âmbito da doutrina estrangeira, ver especialmente ABRAMOVICH, Victor; COURTIS, Christian. Los derechos sociales como derechos exigibles, Madrid: Trotta, 2002, p. 92 ss, embora priorizando, no contexto da obra, os direitos sociais. Sobre a proibição de retrocesso no direito constitucional, enfatizando uma perspectiva compativel com a ordem jurídica nacional, ver também o nosso já referido $A$ eficácia dos direitos fundamentais, p. 434 ss.

20 Cf. MAZZUOLI, op. cit., p. 316 ss. 
alvedrio do legislador nacional a escolha de optar, ou não, pela outorga do status de emenda constitucional aos tratados, ${ }^{21}$ o que justamente parece representar, no fundo, mais um argumento em prol da cogência do novo procedimento a partir da entrada em vigor da EC 45.

Além disso, agora no tocante ao problema da iniciativa legislativa e da participação do Presidente da República no procedimento, impõe-se, ainda, a ressalva - apontada por André Ramos Tavares ${ }^{22}$ - de que, justamente em virtude da sistemática própria dos tratados (que reclamam regular e prévia ratificação e que implica automática submissāo ao Congresso Nacional) a iniciativa do processo de emenda constitucional, haverá de ser, no caso dos tratados em matéria de direitos humanos, sempre do Presidente da República, que detém tanto a competência privativa para a celebração do tratado, quanto a prerrogativa (em regra não exclusiva, à exceção, agora, dos tratados de direitos humanos) da iniciativa das emendas constitucionais (art. 60, inc. II, da CF), dispensada, por óbvio, a ratificação presidencial, de vez que as emendas entram em vigor a partir de sua promulgação pelo Congresso Nacional (art. 60, $\$ 3^{\circ}$, da CF). Cumpre notar, todavia, que a exegese sugerida também parece apontar para o caráter cogente da deliberação por meio do procedimento qualificado das emendas constitucionais.

À vista do exposto, percebe-se que a discussão em torno da obrigatoriedade ou facultatividade da adoção do rito qualificado das emendas constitucionais a partir da vigência da EC 45 segue merecendo um pouco mais de atenção. Com efeito, a prevalecer o entendimento de Valério Mazzuoli, no sentido de que - a despeito das críticas endereçadas contra esta sistemática pelo próprio autor - no concernente à incorporação dos tratados de direitos humanos, passou-se a ter um procedimento dúplice (prévia ratificação e, posteriormente, aprovação - ou não por emenda constitucional) a tramitação de um projeto de emenda constitucional poderia até mesmo ser tida como independente de uma iniciativa específica, pelo menos no sentido de um projeto formalmente e regularmente encaminhado nos termos do art. 60 da CF. Poderia, portanto, bastar que - uma vez aprovado o Decreto Legislativo nos termos do art. 49, inc. I, da CF - este fosse encaminhado (e, neste sentido, transformado) em projeto de emenda constitucional, já no próprio Congresso, o que acaba por conflitar com a tese apresentada por André Tavares no sentido de que a iniciativa deveria sempre ser do Presidente da República. Isto, de fato, poderia ser o caso na hipótese de restar inalterada a atual posição do Supremo Tribunal Federal no que diz com a exigência de Decreto do Executivo para a incorporação definitiva dos tratados, inclusive no caso dos direitos humanos. Neste caso, haveria que se resolver o problema de eventual negativa por parte do Presidente da República em encaminhar o projeto de emenda constitucional (ou a comunicaçāo formal impulsionando o procedimento) para viabilizar, nos termos do art. $5^{\circ}, \mathbb{S} 3^{\circ}$, da $\mathrm{CF}$, a sua aprovação com status de emenda constitucional, de tal

Ibidem, p. 319.

22 Cf. TAVARES, op. cit., p. 45. 
sorte que a posição em prol da iniciativa privativa do Presidente nestes casos se torna ainda mais questionável.

Registre-se, contudo, que a alternativa hermenêutica de acordo com a qual a aprovação pelo rito de emenda constitucional estaria na dependência da prévia ratificação, que, por sua vez, exige já a aprovação pelo Congresso via Decreto Legislativo, não parece ser a mais adequada ou, pelo menos, não se revela como cogente. Com efeito, considerando que a Constituição exige a intervenção do Congresso Nacional no processo de incorporação dos tratados, mas, salvo melhor juízo, não impōe o meio pelo qual se dará a chancela do Legislativo, resulta evidente que a aprovação pelo rito das emendas poderá ocorrer já logo após a celebração do tratado, na primeira oportunidade em que o Congresso for chamado a se manifestar, com ou sem projeto específico de emenda constitucional neste sentido. Convém agregar aqui a observação de que a própria redação do $\$$ $3^{\circ}$ do art. $5^{\circ}$ da CF não exige - além dos requisitos lá estabelecidos - que sejam observados exatamente os mesmos ritos das emendas em geral no que diz com a iniciativa legislativa, o que, na hipótese ventilada, de qualquer modo acaba por ser irrelevante, já que é o Chefe do Executivo quem remete a matéria ao Congresso. Além disso, ainda que o tratado como tal nāo tenha sido ratificado e mesmo que não tenha sido sequer celebrado, nada obsta que por meio de um projeto de emenda constitucional e independentemente de uma vinculação no plano internacional, determinados direitos assegurados em algum tratado sejam também consagrados no plano constitucional.

De outra parte, guarda conexão com este aspecto, a tese - oportunamente invocada por George Galindo - de que limitar a iniciativa das emendas dispondo sobre tratados em matéria de direitos humanos ao Presidente da República, acabaria tornando unilateral a "qualificaçāo" de um tratado como sendo de direitos humanos, já que ao Congresso Nacional caberia apenas aprovar ou rejeitar o status privilegiado do tratado e nāo se pronunciar sobre sua qualidade como tratado de direitos humanos, prejudicando a desejável pluralidade deste processo de qualificação. ${ }^{23}$

Em favor da obrigatoriedade do novo procedimento das emendas constitucionais, para além dos aspectos já ventilados, pode falar também uma (já referida) interpretação teleológico-sistemática a partir da combinação das diretrizes textuais

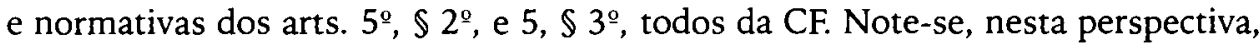
que, adotadas as correçōes hermenêuticas possíveis, com a deliberação uniformizada pelo rito qualificado das emendas à Constituição, evita-se, em primeiro lugar, a possibilidade de existirem tratados em matéria de direitos humanos submetidos a um processo de legitimação mais reforçado e outros nāo, sem falar nas conseqüências jurídicas atreladas a uma aprovação por emendas. A não aprovação do tratado como emenda constitucional, por sua vez, em virtude do procedimento

23 Cf. observações enviadas ao autor do presente ensaio pelo articulista referido em correspondência eletrônica. 
dúplice (ratificação, com aprovação por Decreto Legislativo), não inviabilizaria - a não ser por força de manutenção da jurisprudência equivocada do Supremo Tribunal Federal nesta seara - a possibilidade de se lhes outorgar, nos termos do art. $5^{\circ}, \Im 2^{\circ}$, hierarquia de normas constitucionais (e fundamentais) em sentido material, posição esta que, ao contrário do que tem sustentado parte da doutrina, resulta reforçada e não diminuída para inserção do novo $\$ 3^{\circ}$, já que este - em que pese a sua formulação altamente problemática - apenas veio para afastar a possibilidade de o Supremo Tribunal Federal, pelo menos nos casos de vir a ser promulgada a emenda constitucional relativa a tratado internacional de direitos humanos, questionar a hierarquia constitucional dos mesmos, salvo a hipótese de conflito direto e insanável com as assim designadas cláusulas pétreas de nossa Constituição, o que nos reenvia ao problema da hierarquia normativa desses tratados na ordem interna.

Abordados os problemas selecionados e preponderantemente atinentes a questōes formais (procedimentais) da incorporação, resta discorrer brevemente sobre a questão da hierarquia dos direitos fundamentais (já incorporados ao texto constitucional) em relação ao direito interno, seja ele constitucional ou infraconstitucional.

No tocante a essa problemática, é possível afirmar que o novo $\$ 3^{\circ}$ representou - num certo sentido - um significativo avanço ao assegurar, desde que observado o procedimento nele estabelecido, uma hierarquia constitucional derivada e sempre supralegal dos direitos consagrados nos tratados, impedindo, nestes casos, a manutenção do princípio da paridade entre lei ordinária e tratado ainda prevalente na jurisprudência do Supremo Tribunal Federal e sustentado, embora cada vez menos, por parte da doutrina. Também é correto afirmar que, com isso, ainda não foi resolvida (pelo menos não como tem anunciado alguns entusiasmados defensores da reforma) a questão da hierarquia constitucional, em se considerando as relações entre o tratado incorporado (equivalente às emendas) e o texto constitucional originário. Convém relembrar, especialmente nesta quadra, que as emendas constitucionais podem ser declaradas inconstitucionais em caso de conflito com as assim designadas cláusulas pétreas da nossa Constituição, que abrangem tanto os limites materiais explícitos (art. $60, \$ 4^{\circ}$ ), quanto os limites materiais implícitos, estes reconhecidos pela maioria da doutrina, ainda que não haja consenso quanto aos direitos que integram o rol dos limites materiais implícitos. Ainda que se parta do pressuposto de que uma eventual restrição ou ajuste do conteúdo dos limites materiais não necessariamente enseja uma inconstitucionalidade da emenda (aplicando-se a tese da imunidade apenas do núcleo essencial de cada princípio ou direito fundamental) ${ }^{24}$ é certo que a possibilidade de conflito é real, já que inevitáveis inclusive as colisōes entre os próprios direitos fundamentais originariamente assegurados pelo Constituinte, bastando relembrar aqui a tão discutida questão da prisão civil do depositário infiel e do duplo grau de juris-

24 Sobre o ponto, ver o nosso $A$ eficácia dos direitos fundamentais, p. 428 ss. 
dição, entre outras possibilidades. ${ }^{25}$ No mínimo, não se pode deixar de admitir a possibilidade de uma interpretação que venha a reconhecer um conflito insanável por uma interpretação conforme e que, por via de conseqüência, possa resultar em uma declaração de inconstitucionalidade de um ou mais aspectos do tratado (emenda) por violação das cláusulas pétreas.

Seguindo esta linha de raciocínio e em se partindo da premissa de que não há necessariamente uma hierarquia abstrata entre normas formalmente (e, em regra, também materialmente) constitucionais e normas apenas materialmente constitucionais, a própria incorporação mediante emenda poderia até mesmo, a depender da exegese do novo $\$ 3^{\circ}$, ser desvantajosa em relação ao sistema anterior, a não ser que o Supremo Tribunal Federal passasse a assegurar - como há muito deveria tê-lo feito - a hierarquia materialmente constitucional dos tratados em matéria de direitos humanos, mesmo que incorporados por Decreto Legislativo. Neste caso, a solução de eventual conflito entre os direitos da Constituição e os dos tratados incorporados deveria observar, consoante já sustentado no segmento anterior, os princípios hermenêuticos que regem os conflitos entre os direitos e princípios originariamente reconhecidos pelo Constituinte, portanto, que exigem uma exegese sistemática e direcionada por uma adequada ponderação dos interesses (valores) em pauta, sempre privilegiando, como destacado alhures, uma solução mais favorável à garantia da dignidade da pessoa. ${ }^{26}$

De qualquer modo, não nos parece correto argumentar - notadamente em favor da tese da inconstitucionalidade substancial do $\$ 3^{\circ}$ do art. $5^{\circ}-$ que o sim-

25 Cf. também a lembrança de GALINDO, op. cit., p. 11 ss.

26 Que tal solução, igualmente apontada por expressiva doutrina, por si só não afasta compulsoriamente a possibilidade de prisāo do depositário infiel, não tem sido suficientemente percebido e discutido. Embora não seja o nosso intento - até mesmo em face da limitação espacial a que estamos sujeitos - desenvolver este tópico, certo é que não se poderá afastar de plano a tese de que no conflito entre o direito internacional dos direitos humanos e as previsōes constitucionais, ambas situadas no mesmo plano hierárquico, uma ponderaçāo de bens poderia, a depender da constelação fática e normativa, ser desfavorável ao depositário. Bastaria, neste contexto, imaginar que no conflito entre uma temporária restrição da liberdade pessoal (que, por si só, não pode ser considerada como violação da dignidade, já que do contrário qualquer pena de prisão, mesmo que aplicada em condiçōes compatíveis com a dignidade, seria descabida) e a garantia subjetiva (individual ou coletiva) e objetiva do acesso a um sistema judiciário efetivo e que encontra na penhora e na correspondente figura do depósito judicial uma de suas principais formas de concretização, a balança do intérprete poderia vir a pender - sem romper com a premissa da hierarquia constitucional dos tratados - em favor da permissão constitucional da prisão civil nesta hipótese. $O$ argumento de que no caso da expressa previsão da prisão civil do depositário não se cuida propriamente de uma norma definidora de direito e garantia fundamental igualmente merece ser tomado com certa reserva, já que, a depender da interpretaçāo pela qual se optar, cuida-se de restriçāo a direito com o intuito de assegurar outros, tanto eventual direito do autor da demanda judicial (e que nem sempre está a discutir interesse meramente patrimonial) quanto o direito e garantia da tutela jurisdicional efetiva. Resulta evidente, contudo, que tal linha argumentativa aponta para a possibilidade excepcional e sempre carente da análise da sua legitimaçāo constitucional da prisāo civil do depositário (portanto, sempre condicionada à demonstraçāo da necessidade de salvaguardar outro bem fundamental e de modo compativel com os critérios da proporcionalidade) e jamais poderia servir para justificar a aplicação do instituto da prisāo civil na generalidade dos casos, notadamente quando em causa interesses eminentemente patrimoniais. Cuida-se, todavia, de debate a ser aprofundado e que, a despeito de tudo o que já se escreveu, reclama uma renovação. 
ples fato de os tratados posteriores à EC 45 poderem (ou deverem, a depender da posição adotada) ser aprovados por emenda constitucional, conduziria inexoravelmente a uma decisāo em prol da hierarquia meramente legal dos tratados anteriores, embora certamente não se possa descartar esta alternativa interpretativa. ${ }^{27}$ No tocante a este ponto, consideramos estar diante de um falso problema, visto que, como já demonstrado, a nova disposição introduzida pela EC 45 pode ser compreendida como reforçando o entendimento de que os tratados anteriores, já por força do art. $5^{\circ}, \$ 2^{\circ}$, da $C F$, possuem hierarquia materialmente constitucional, sem falar na interpretação - igualmente colacionada, mas aqui questionada - de acordo com a qual os tratados anteriores teriam sido recepcionados como equivalentes às emendas constitucionais pelo novo $\$ 3^{\circ}$ do art. $5^{\circ}$. Pelo menos, se em tese é possível que o entendimento adotado pelo Supremo Tribunal Federal seja o da manutenção de sua jurisprudência atual, no sentido da hierarquia legal dos tratados, não o será necessariamente em virtude do teor do $\$ 3^{\circ}$ do art. $5^{\circ}$, já que a tese da paridade entre lei e tratado é anterior.

Por outro lado, para afastar o argumento de que mesmo vindo a prevalecer (no âmbito do próprio Supremo Tribunal Federal) a tese da hierarquia constitucional, remanesceria problemática a situação de conflito entre os tratados incorporados por emenda e as cláusulas pétreas da Constituição, já que, nesta hipótese, poderia a nossa Corte Suprema declarar a inconstitucionalidade da emenda que incorporou o tratado. Embora correto o argumento, igualmente não nos parece que esta seja a única conclusão possível, ainda mais em se privilegiando uma exegese teleológico-sistemática, que parte do princípio da prevalência dos direitos humanos nas relações internacionais (art. $4^{\circ}$, inc. II) e, de modo especial, de uma leitura conjugada do conteúdo normativo dos arts. $5^{\circ}, \mathbb{2} 2^{\circ}$, e $5^{\circ}, \mathbb{3} 3^{\circ}$, todos da CF. Neste sentido, há que destacar a tese de que a inovação trazida pela Reforma do Judiciário pode ser interpretada simplesmente como assegurando hierarquia pelo menos materialmente constitucional a todos os direitos fundamentais (já que, uma vez incorporados, os direitos humanos passam também - e acima de tudo - a serem todos fundamentais) e, também, formalmente constitucional aos tratados incorporados pelo rito de emenda constitucional, ${ }^{28}$ que, de resto, receberiam (de vez que alguma diferenciação nos parece inevitável) um tratamento distinto (no sentido de mais reforçado) quanto ao fato de se integrarem à Constituição textual e enrobustecerem a tese da impossibilidade de uma posterior denúncia do tratado e da responsabilização até mesmo interna se este vier a ocorrer. Com isso, mediante a chancela da posição de que sempre todos os direitos fundamen-

\footnotetext{
Ver, neste sentido, o ceticismo de GALINDO, op. cit., p. 12, bem como o desenvolvimento do tópico na nota $\mathrm{n}^{\circ} 20$, igualmente apontando para a possibilidade de, a depender da opçāo do Legislador no sentido de reaprovar apenas parte dos tratados já incorporados ao ordenamento interno (no caso, antes da EC 45/2004), de se estabelecer um sistema diferenciado entre tratados de direitos humanos com hierarquia constitucional (quando e se aprovados pelo rito das emendas) e com hierarquia legal, o que, de resto, poderia contribuir para piorar a já tensa relaçāo entre o direito internacional e o direito nacional, tal qual atualmente verificável no caso do Brasil.
}

28. Neste sentido, a posição sustentada, entre outros, especialmente por PIOVESAN, op. cit., p. 72-73. 
tais (incorporados, ou não, por emenda constitucional) possuem status materialmente constitucional - compreendido sempre no sentido de uma igual dignidade constitucional - eventual situação conflitiva (mesmo em se cuidando de contraste entre emenda e disposiçōes fundamentais da Constituição originária) haveria de se resolver, até mesmo para impedir um tratamento incoerente e inconsistente de tais conflitos no âmbito do sistema constitucional, pelas mesmas diretrizes hermenêuticas, tendo como norte a solução mais afinada com a máxima salvaguarda da dignidade da pessoa humana, mais de uma vez - e, convém que assim o seja -, colacionada neste ensaio.

Assim, se é certo que comungamos da posição bastante difundida de que talvez melhor tivesse sido que o reformador constitucional tivesse renunciado a inserir um $\mathbb{S} 3^{\circ}$ no art. $5^{\circ}$ ou que (o que evidentemente teria sido bem melhor) - em entendendo de modo diverso - tivesse se limitado a expressamente chancelar a incorporação automática (após prévia ratificação) e com hierarquia constitucional de todos os tratados em matéria de direitos humanos, com a ressalva de que no caso de eventual conflito com direitos previstos pelo Constituinte de 1988 , sempre deveria prevalecer a disposição mais benéfica para o ser humano (proposta esta formulada, nestes termos, por Valério Mazzuoli), também é correto que vislumbramos no dispositivo ora analisado um potencial positivo, no sentido de viabilizar alguns avanços concretos em relação à práxis ora vigente entre nós. Que uma posterior alteração do próprio $\mathbb{\$} 3^{\circ}$, por força de nova emenda constitucional, resta sempre aberta, ainda mais se for para aprimorar e, portanto, reforçar a proteção dos direitos fundamentais oriundos dos tratados internacionais de direitos humanos, justamente nos parece servir de estímulo para um esforço hermenêutico construtivo também nesta seara.

\section{Considerações finais}

À vista de todo o exposto e cientes de que apenas tivemos condiçōes de esgrimir alguns argumentos em torno de algumas das possibilidades hermenêuticas suscitadas (e ainda por suscitar) em torno do novo $\$ 3^{\circ}$ do art. $5^{\circ}$ da $C F$, não se poderá olvidar que todas as alternativas referidas estarão sempre sujeitas ao crivo da jurisprudência (vinculante!?) do Supremo Tribunal Federal. Que isto também se aplica a eventual julgamento sobre a própria constitucionalidade do $\$ 3^{\circ}$ resulta evidente, de tal sorte que, a despeito de algumas vozes a sustentar a tese da inconstitucionalidade substancial da inovação, não nos parece que seja esta necessariamente a melhor (e muito menos a única) exegese possível, ${ }^{29}$ até mesmo pelo fato de que, se o argumento estiver calcado especialmente na resistência de

29 Sobre a tese da melhor resposta possível, em detrimento da tese da única resposta correta, ver a esclarecedora e erudita contribuição de Juarez Freitas, A Melhor Interpretação Constitucional Versus a Única Resposta Correta. Virgílio Afonso da Silva (Org.). Interpretação Constitucional, São Paulo: Malheiros, 2005, p. 317-356. 
(ainda) boa parte dos integrantes da nossa Corte Suprema em relação à hierarquia constitucional dos tratados em matéria de direitos humanos, também não se poderá esperar que esta mesma Corte, em eventualmente se posicionando pela inconstitucionalidade (o que justamente não nos parece provável), passasse a, de uma hora para outra, posicionar-se em favor da hierarquia constitucional destes tratados, na condição de materialmente constitucionais e fundamentais.

Além do mais, o argumento de que com a inserção do novo $₫ 3^{\circ}$ no art. $5^{\circ}$ da CF teria ocorrido uma restrição do próprio regime da fundamentalidade dos direitos oriundos de tratados internacionais revela-se problemático pelo fato de que tal restrição, como já demonstrado, não necessariamente resulta em violação do núcleo essencial do art. $5^{\circ}, \mathbb{S} 2^{\circ}$, da $\mathrm{CF}$, especialmente em face da existência de alternativas interpretativas idôneas. Nesta mesma linha de entendimento, resulta pelo menos discutível a tese de que poderia haver uma inconstitucionalidade de emenda constitucional que estivesse em conflito com uma determinada interpretação a respeito do regime de direitos fundamentais, ainda mais quando tal interpretação é objeto de importante dissídio na doutrina e jurisprudência. Importa, portanto, que também neste contexto reste consignada a lição de Lenio Luiz Streck, no sentido de que ao intérprete não é conferida a possibilidade de "dizer qualquer coisa sobre qualquer coisa", ${ }^{30}$ já que sempre sujeito aos limites textuais mínimos (explícitos e implícitos) estabelecidos pelo sistema constitucional.

Assim, dadas as opções discutidas (que não voltarão aqui a ser retomadas e avaliadas, até mesmo por nāo ser o nosso intuito enunciar qualquer conclusão fechada em relação às mesmas), verifica-se que há como outorgar ao novo $\$ 3^{\circ}$ do art. 5\% uma interpretação que, a despeito de alguns aspectos problemáticos, lhe assegura um sentido útil e não necessariamente retrocessivo, valorizando o regime jurídico-constitucional dos tratados de direitos humanos anteriores e posteriores à vigência da EC 45. De outra parte, também não se haverá de ver no novo dispositivo apenas uma "fórmula de compromisso" destinada a resolver o problema da incorporação diferenciada dos tratados internacionais de direitos humanos em relação a outros documentos internacionais. ${ }^{31}$ Que a ocorrência de um possível avanço em termos substantivos depende, em primeiro plano, dos esforços sérios e conjugados da doutrina e da própria jurisprudência constitucional no plano do controle difuso, no sentido de tornar produtivo o princípio da interpretação conforme a Constituição, resulta evidente. O processo democrático - ainda que de modo distinto do que ocorre com o legislativo e o executivo - também permeia o modo de produção do direito jurisprudencial, especialmente no que diz com o

30 Cf. STRECK, Lenio Luiz. Hermenêutica jurídica e $(m)$ crise. 5. ed. Porto Alegre: Livraria do Advogado, 2004, p. 310 ss, bem analisando o cunho não-relativista da hermenêutica.

31 Neste sentido, ver as ponderaçōes de MORAIS, José Luis Bolzan de. Artigo $5^{\circ}$ : as crises do Judiciário e o acesso à justiça. In: AGRA, Walber de Moura (Org.). Comentários à reforma do poder judiciário. Rio de Janeiro: Forense, 2005 , p. 53 , apontando para a possibilidade de se deduzir do novo $\$ 3^{\circ}$ do art. $5^{\circ}$ uma espécie de "fórmula de compromisso", mas questionando, com razāo, a correção deste entendimento. 
pluralismo que caracteriza o processo decisório nos órgãos colegiados e com a possibilidade (mesmo que já mais restrita, em virtude da expansão do controle concentrado) de uma co-participação ativa de todos os órgãos jurisdicionais e da intervençāo social, notadamente por meio das partes e seus representantes, assim como por meio do Ministério Público (isto sem falar na figura salutar do amicus curiae no processo de controle abstrato) implica a valorização da concepção de uma sociedade aberta dos intérpretes da Constituição (Häberle) e a necessidade de se levar em conta eventuais câmbios hermenêuticos.

Por derradeiro, frise-se que a discussão recém-retomada com outro alento, até mesmo como decorrência das incongruências resultantes da fórmula adotada pelo reformador constitucional, nos possibilita buscar, também no que diz com a relevante problemática da incorporação e força normativa dos direitos fundamentais oriundos dos tratados internacionais de direitos humanos, uma saída viável para que - como bem advertiu Celso de Albuquerque Mello - não permaneçamos sendo "um país cristalizado na nossa miséria econômica, social e jurídica". ${ }^{32}$ Tal desafio representa, já por si só, um motivo mais do que suficiente para seguir investindo no tema, até mesmo pelo fato de que a meta da melhor resposta possível - e, portanto, sempre constitucionalmente adequada - constitui também um processo de permanente construção e reconstrução do Direito. Assim, apenas a evolução do debate e exegese que efetivamente vier a ser implementada pelo Judiciário e pelo Legislador ao tema poderão revelar se estamos, ou não, vivenciando um retrocesso em matéria de proteção dos direitos humanos e dos direitos fundamentais.

\section{Referências}

ABRAMOVICH, Victor; COURTIS, Christian. Los derechos sociales como derechos exigibles. Madrid: Trotta, 2002.

COSTA, Aldo de Campos. Direitos humanos. Disponível em: < http://www.unb. $\mathrm{br} / \mathrm{fd} /$ colunas_Prof/aldo_campos/aldo_0l.htm >. Acesso em: $12 \mathrm{fev} .2006$.

FRANCISCO, José Carlos. Bloco de constitucionalidade e recepção dos tratados internacionais. In: TAVARES, André Ramos; LENZA, Pedro; ALARCON, Pietro de Jesus Lora (Org.). Reforma do judiciário analisada e comentada. São Paulo: Método, 2005.

GALINDO, George Rodrigo Bandeira. A Reforma do Judiciário como retrocesso para a proteção internacional dos direitos humanos: um estudo sobre o novo $\mathbb{\$} 3^{\circ}$ do artigo $5^{\circ}$ da Constituição Federal, Cena Internacional, Ano 7, no 1, 2005, p. 1-22.

32 Cf. MELLO, Celso Antonio Bandeira de. $O \$ 2^{\circ}$ do art. $5^{\circ}$ da Constituição Federal. In: TORRES, Ricardo Lobo (Org.). Teoria dos direitos fundamentais. 2. ed. Rio de Janeiro: Renovar, 1999, p. 29. 
FREITAS, Juarez. A interpretação sistemática do direito. 4. ed. São Paulo: Malheiros, 2004.

FREITAS, Juarez. A melhor interpretação constitucional versus a única resposta correta. SILVA, Virgílio Afonso da (Org.). Interpretação constitucional. São Paulo: Malheiros, 2005, p. 317-356.

LOPES, Anselmo Henrique Cordeiro. A força normativa dos tratados internacionais de direitos humanos e a Emenda Constitucional n 45/2004. Disponível em: <http:// www1.jus.com.br/doutrina/texto.asp?id=6157>. Acesso em: 12 fev. 2006.

MAZZUOLI, Valério de Oliveira. O novo $\$ 3^{\circ}$ do art. $5^{\circ}$ da Constituição e sua eficácia. Revista da Ajuris, v. 32, n 98, Porto Alegre, jun. 2005, p. 303-332.

MELlO, Celso Antonio Bandeira de. O $\$ 2^{\circ}$ do art. $5^{\circ}$ da Constituição Federal. In: TORRES, Ricardo Lobo (Org.). Teoria dos direitos fundamentais. 2. ed. Rio de Janeiro: Renovar, 1999.

MORAIS, José Luis Bolzan de. Artigo $5^{\circ}$ : as crises do Judiciário e o acesso à justiça. In: AGRA, Walber de Moura (Org.). Comentários à reforma do poder judiciário. Rio de Janeiro: Forense, 2005.

PIOVESAN, Flávia. Reforma do judiciário e direitos humanos. In: TAVARES, André Ramos; LENZA, Pedro; ALARCON, Pietro de Jesus Lora (Org.). Reforma do judiciário analisada e comentada. São Paulo: Método, 2005.

RAMOS, André de Carvalho. Teoria geral dos direitos humanos na ordem internacional. Rio de Janeiro: Renovar, 2005.

SARLET, Ingo Wolfgang. A eficácia dos direitos fundamentais. 6. ed. Porto Alegre: Livraria do Advogado, 2006.

SGARBOSSA, Luís Fernando. A emenda constitucional n45/04 e o novo regime jurídico dos tratados internacionais em matéria de direitos humanos. Disponível em: <http:// www1.jus.com.br/doutrina/texto.asp?id=6272>. Acesso em: 11 fev. 2006.

STRECK, Lenio Luiz. Hermenêutica jurídica $e(m)$ crise. 5. ed. Porto Alegre: Livraria do Advogado, 2004.

TAVARES, André Ramos. Reforma do judiciário no Brasil pós-88: (des)estruturando a justiça. Comentários completos à emenda constitucional n ${ }^{\circ} 45 / 04$. São Paulo: Saraiva, 2005. 